Article

\title{
Improving the Estimation of Above Ground Biomass Using Dual Polarimetric PALSAR and ETM+ Data in the Hyrcanian Mountain Forest (Iran)
}

\author{
Sara Attarchi ${ }^{1, *}$ and Richard Gloaguen ${ }^{1,2}$
}

1 Remote Sensing Group, Institute of Geology, TU Bergakademie Freiberg (TUBAF), Bernhard-von-Cotta-Str. 2, D-09599 Freiberg, Germany

2 Remote Sensing Group, Helmholtz Institute Freiberg of Resource Technology, Halsbruecker Str. 34, D-09599 Freiberg, Germany; E-Mail: r.gloaguen@hzdr.de

* Author to whom correspondence should be addressed; E-Mail: s_atarchi@yahoo.com; Tel.: +49-373-139-2806; Fax: +49-373-139-3599.

Received: 16 December 2013; in revised form: 17 April 2014 / Accepted: 18 April 2014 / Published: 28 April 2014

\begin{abstract}
The objective of this study is to develop models based on both optical and L-band Synthetic Aperture Radar (SAR) data for above ground dry biomass (hereafter AGB) estimation in mountain forests. We chose the site of the Loveh forest, a part of the Hyrcanian forest for which previous attempts to estimate AGB have proven difficult. Uncorrected ETM+ data allow a relatively poor AGB estimation, because topography can hinder AGB estimation in mountain terrain. Therefore, we focused on the use of atmospherically and topographically corrected multispectral Landsat ETM+ and Advanced Land-Observing Satellite/Phased Array L-band Synthetic Aperture Radar (ALOS/PALSAR) to estimate forest AGB. We then evaluated 11 different multiple linear regression models using different combinations of corrected spectral and PolSAR bands and their derived features. The use of corrected ETM+ spectral bands and GLCM textures improves AGB estimation significantly (adjusted $R^{2}=0.59$; RMSE $=31.5 \mathrm{Mg} / \mathrm{ha}$ ). Adding SAR backscattering coefficients as well as PolSAR features and textures increase substantially the accuracy of AGB estimation (adjusted $R^{2}=0.76$; RMSE $=25.04 \mathrm{Mg} / \mathrm{ha}$ ). Our results confirm that topographically and atmospherically corrected data are indispensable for the estimation of mountain forest's physical properties. We also demonstrate that only the joint use of PolSAR and multispectral data allows a good estimation of AGB in those regions.
\end{abstract}


Keywords: Landsat7/ETM+; ALOS/PALSAR; L-band; above ground biomass (AGB); DBH; linear multiple regression; topographic effects; Hyrcanian mountainous forest; Iran

\section{Introduction}

In this study, we developed forest AGB models based on ETM+ and ALOS/PALSAR data in the Loveh forest, a mountainous and high biomass forest located in northern Iran. This forest is of interest because it is increasingly fragmented, degraded and converted to other forms of land use [1]. As many other forests in Western and Central Asia it is located in a rugged terrain. To our knowledge, limited studies used remote sensing approaches to investigate the biodiversity, species richness and forest structure in this forest [1,2]. Because of its complexity, no attempt on biomass estimation was performed before. Therefore, the retrieval of biophysical properties over the Loveh forest remains challenging.

Information about forest stand structure and the quantification of AGB are of great importance to assess forest ecosystem productivity, determine carbon budget and support studies of the role of forests in the global carbon cycle [3-8]. The existing biomass estimation methods that rely on forest inventory data and allometric equations are accurate. However, they have two main disadvantages. First, they are expensive, time-consuming and they cannot provide the spatial distribution of biomass in large areas. Second, forest inventory data and allometric models are rarely available for specific forested environments $[9,10]$.

Optical remote sensing data have proven to be a powerful means for biomass estimation [4,11]. However, the use of these data has some limitations such as model dependency on in situ data as well as low spectral saturation levels [9,12]. Estimation of forest biomass by means of optical remote sensing still remains challenging especially in a forest with dense canopy or complex structure as well as in high relief areas $[9,12]$. Active remote sensing data like SAR overcome some limitations of optical data. They have the advantage to be weather and daylight independent $[9,13]$. SAR backscatter correlates with forest biomass, particularly in low-medium biomass forest at lower frequencies like $\mathrm{P}$ and L-bands [14-17].

Polarized SAR at L-bands (e.g., ALOS/PALSAR) have been successfully used for estimating AGB due to the high sensitivity of the backscattered signal at L-bands to forest structure, probably because of strong interactions with tree trunks and branches [18-21]. Usually, L-bands fail for high amounts of biomass (i.e., ca. $>100 \mathrm{Mg} / \mathrm{ha}$ ), because of saturation problems i.e., loss of sensitivity to forest biophysical parameters [19,21-23].

Previous studies show that L-band backscattering tends to increase with increasing canopy cover, density and size of the tree [19,24-26]. Both co-polarized (HH and VV) and cross-polarized (HV and $\mathrm{VH})$ of L-bands are sensitive to forest biomass [19,27,28]. Usually, cross-polarized backscatter data display a larger dynamic range compared to co-polarized bands [19,25,29].

Several studies investigated the integration of SAR and multispectral remote sensing data for the estimation of forest biophysical properties [6,17,30]. Ahmed et al. [31] observed promising correlations among high AGB values (>100 Mg/ha) and radar backscatter of ALOS/PALSAR and NASA JPL's Uninhabited Aerial Vehicle Synthetic Aperture Radar (UAVSAR) over the Harvard 
forest in the United States, despite the fact that saturation of L-band occurs at high AGB. Thus, the joint usage of SAR and optical data for estimating AGB appears promising but still needs more investigation [6]. All of the mentioned studies were not in mountain forests probably because the estimation of forest structure parameters is strongly affected by the relief [5,32-35]. Heterogeneous topography causes changes in backscattering mechanisms and induced large surface reflectance variations [5,36]; hence, topographic corrections are necessary for the minimization of such effects [6].

The main objective of this study is to improve the estimation of biomass in rugged terrain forests. We first evaluate the predictive power of ETM+ reflectance and ALOS/PALSAR backscattering intensity. We then show the effect of the terrain corrections and finally develop an approach based on multiple linear regressions in order to jointly use PolSAR and multispectral data and some pertinent derived features such as textures and PolSAR decompositions.

First, we describe the study area as well as field and remote sensing data. Then, we detail the preprocessing procedures and the extraction of specific metrics allowing a better description of forest structures. We then develop the calculation of forest AGB based on the allometric equation and the multiple linear regressions used in this study.

\section{Study Area and Data}

\subsection{Study Area and Field Data}

The study area is the Loveh forest, a subset of the Hyrcanian forest that stretches over the northern slopes of the Alborz mountains and the southern coast of the Caspian sea. The natural vegetation is a temperate deciduous broadleaved forest [37,38]. The Loveh forest extends from $37^{\circ} 14^{\prime}$ to $37^{\circ} 24^{\prime} \mathrm{N}$ and $55^{\circ} 33^{\prime}$ to $55^{\circ} 47^{\prime} \mathrm{E}$ (comprises $c a .10,683$ ha) in the north east of Iran (Figure 1). Based on SRTM data, elevation ranges from 190-1900 $\mathrm{m}$ above mean sea level, while slopes vary between $6^{\circ}$ and $16^{\circ}$ based on shuttle radar topography mission (SRTM) data. Annual mean temperature and precipitation are $12.2^{\circ} \mathrm{C}$ and $524 \mathrm{~mm}$ [39]. Its main tree species are Quercus castaneafolia, Carpinus betulus, Acer cappadocicum, Cerasus avium, Tilia begonifolia, Diospyros lotus, and Parrotia persica [1,39].

Figure 1. Location of the study area (red rectangle) in northern Iran. The land cover map is reclassified from $500 \mathrm{~m}$ MODIS land cover map.

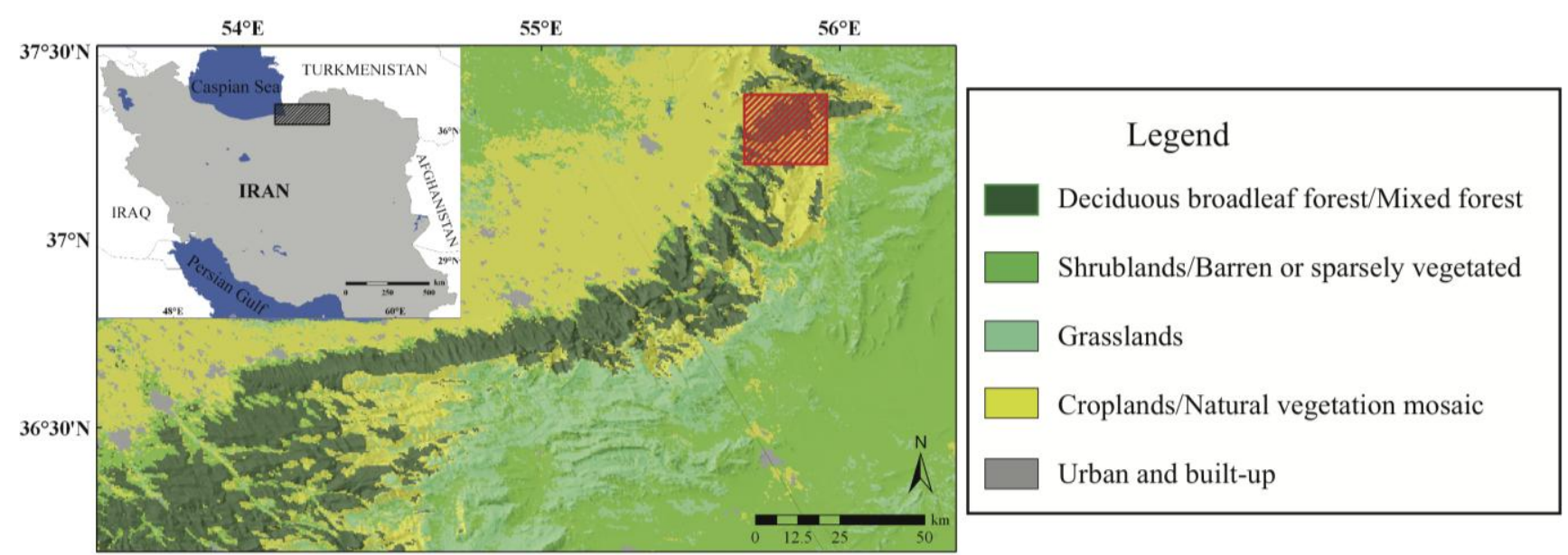


This forest has been treated by the shelter-wood method since 1963. In 2003, the treatment method was replaced by a selective logging method. As a result, the vertical structure of the forest has been modified. Three different stand age classes are found due to these logging activities (Table 1). Preparatory and establishment cuts provided more light and space for new seedlings to grow in managed forest [40]. Therefore, tree densities increase in managed forest compared to natural forest [39]. The maximum tree density belongs to MF2, where the long treatment allows for more seedlings to establish. Because of the existence of some mature trees in MF1 class [41], the tree diameter at breast height (measured at $1.3 \mathrm{~m}$; DBH) and basal area values are higher than MF2 class [39]. However, the largest DBH and basal areas are observed in natural forest (NF) (Figure 2) [39].

Table 1. Characteristics of three selected forest types.

\begin{tabular}{|c|c|}
\hline Forest Stand Age & Characteristics \\
\hline Natural forest (NF) & $\begin{array}{l}\text { The forest has not been affected by any treatment. Trees have closed crown cover. } \\
\text { This forest has more developed vertical stratification, and fewer trees per ha } \\
\text { compared to managed forests. It is also composed of trees with larger DBH [39]. }\end{array}$ \\
\hline $\begin{array}{l}\text { Managed forest } 1 \text { (MF1) } \\
\text { (5-25 years) }\end{array}$ & $\begin{array}{l}\text { Forest area, which is managed by shelter-wood method. Preparatory cut, seed } \\
\text { cut, and establishment cut were done according to a } 25 \text {-year time plan. The } \\
\text { removal cut still is not done, so some trees with large DBH can be found [39]. }\end{array}$ \\
\hline $\begin{array}{c}\text { Managed forest } 2 \text { (MF2) } \\
\quad(25-45 \text { years })\end{array}$ & $\begin{array}{l}\text { Forest area which is also managed by shelter-wood method for } 45 \text { years. } \\
\text { Preparatory cut, seed cut as well as establishment and removal cut were done. } \\
\text { In average, density of trees (number per ha) is higher, and trees' DBH are } \\
\text { smaller compared to other classes [39]. }\end{array}$ \\
\hline
\end{tabular}

Field inventory was carried out in 99 square plots $(60 \times 60 \mathrm{~m})$ during the summer of 2004 [1]. Handheld GPS measurements were used to register the geographic center of each sample plot. DBH as well as the number of trees were measured and tree species were recorded in each plot. Trees with DBH below $7.5 \mathrm{~cm}$ were not included in the survey.

Figure 2. The distribution of (a) mean DBH and (b) number of trees per ha for the field plots located in three different forest stand age classes.
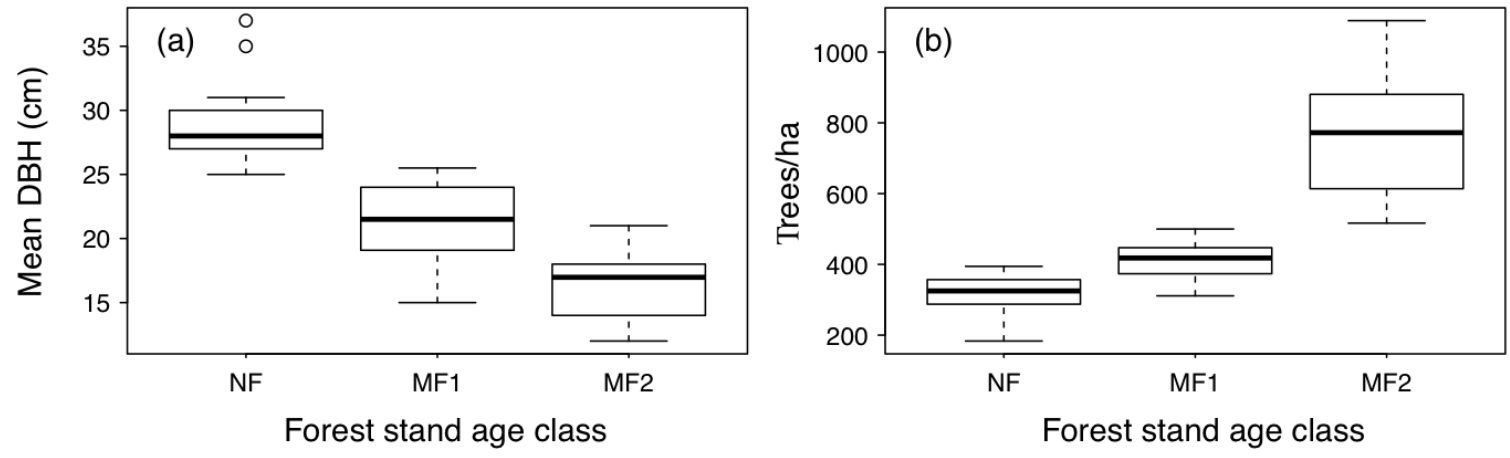

\subsection{Remote Sensing Data}

The Landsat ETM+ scene used in this study was acquired on 10 September 2007. Six reflective bands consisting of visible and shortwave infrared wavelengths with $30 \mathrm{~m}$ spatial resolution were used (Table 2). Thermal and panchromatic bands were not included in this investigation. 
ALOS/PALSAR fine beam double polarization (FBD) at $\mathrm{HH}$ and $\mathrm{HV}$ was acquired on 27 September 2007 (Table 2). The scene was delivered in slant range single look complex (SLC) format (level 1.1). Our first concern was SAR data availability; therefore, there is inevitable time shift between field data and remote sensing data. We accepted this time shift as one of the limitation for developing AGB estimation model. Given our knowledge of forest growth in this area, the delay between remote sensing data acquisition and field survey will not affect biomass prediction.

Table 2. Remote sensing data used in this study.

\begin{tabular}{ccc}
\hline Satellite Sensor & Image Acquisition Date & Spatial Resolution \\
\hline Landsat7/ETM+ & 10 September 2007 & Six visible and shortwave infrared bands with $30 \mathrm{~m}$ \\
& 27 September 2007 & With $12.5 \mathrm{~m}$ pixel spacing (resample to $30 \mathrm{~m}$ ) \\
ALOS/PALSAR & L-band HH and HV & $90 \mathrm{~m}$ spatial resolution (resample to $30 \mathrm{~m}$ ) \\
\hline
\end{tabular}

Digital elevation model (DEM) from SRTM with 3 arc-second spatial resolution (90 m) from U.S. Geological Survey (USGS) was obtained. We then resampled the DEM to $30 \mathrm{~m}$ resolution using cubic convolution interpolation (Table 2).

\section{Methodology}

\subsection{Above Ground Biomass Calculation}

We used diameter-based allometric equations to calculate forest AGB from DBH data measured in the field (Equation (1), [42]). There is no specific allometric equation for the Hyrcanian forest; therefore, we used a general and not-site specific allometric equation which is adjusted for all tree species based on DBH data $[43,44]$.

$$
\mathrm{AGB}=a(\mathrm{DBH})^{b}
$$

$a=0.0566, b=2.663$ [42], AGB $=$ the total above ground tree dry biomass $(\mathrm{kg} /$ tree $), \mathrm{DBH}(\mathrm{cm}) . \mathrm{DBH}$ : ranges from $3.8-63 \mathrm{~cm}[42]$.

Once forest AGB was calculated using the DBH of all trees in each plot, we summed up all the values and converted them to $\mathrm{Mg} / \mathrm{ha}$. We chose the above formula, which is applicable to various $\mathrm{DBH}$ values as in the study area. According to West [45], the scaling coefficient $a$ is not necessarily species and site dependent $[43,46]$. We chose the value of 0.0566 , adopted for all tree species according to [42]. A universal value of around 2.66 has been suggested for the scaling exponent $b[43,45]$. As the AGB estimation is dependent on allometric equations, we also tested the modeling of DBH.

Table 3. Summary of field forest AGB (Mg/ha).

\begin{tabular}{cccc}
\hline Forest Stand Age & Mean & STD & Range \\
\hline Natural forest & 254.27 & 29.9 & $176.34-343.38$ \\
Managed forest 1 & 195.93 & 44.74 & $88.22-297.44$ \\
Managed forest 2 & 142.14 & 32.73 & $64.45-267.84$ \\
\hline
\end{tabular}


Table 3 summarizes calculated forest AGB based on field data by using the allometric equation in different forest stand age classes. Plots of natural forest have high AGB. Average values of AGB in these plots are $254.27 \mathrm{Mg} / \mathrm{ha}$. Plots of managed forests have lower value compared to natural forest. Minimum AGB values belong to the MF2, and the AGB values of MF1 remain between these two classes.

\subsection{Landsat Processing}

First we corrected Landsat scene ETM+ for scan line corrector (SLC) error using one successive scene. The filled scene should be selected in the way that both scenes have the highest possible spectral, temporal and radiometric consistency [47]. The number of needed filled scenes is determined based on the gaps overlapping between scenes [48]. We selected the image acquired on 12 October 2007 as the filled scene, because its acquisition date is close to that of the base image and it is mostly free of clouds. As the corresponding pixels of the base image are scanned on the filled scene, there was no need to use more filled scenes [49]. The correction was done in two steps. First, the two scenes have been aligned to a common frame, then the gaps caused by SLC-off were replaced with the filled scene [50]. After removing the SLC-off error, we calculated at sensor radiance from digital number (DN), taking into account the gain and bias of the sensor. In the next step, radiance was converted to surface reflectance using ATCOR-3 [51] and SRTM. We also evaluated the ATCOR-2 [51] without a $\mathrm{DEM}$, in order to verify the impact of relief on the surface reflectance. In mountainous forests, relief can considerably affect forest reflectance, resulting in spurious relationships between AGB and reflectance [6].

Figure 3. A pseudo-color composite of the Landsat-7/ETM+ (R4:G3:B2) acquired on 10 September 2007 (a) before and (b) after topographic correction.

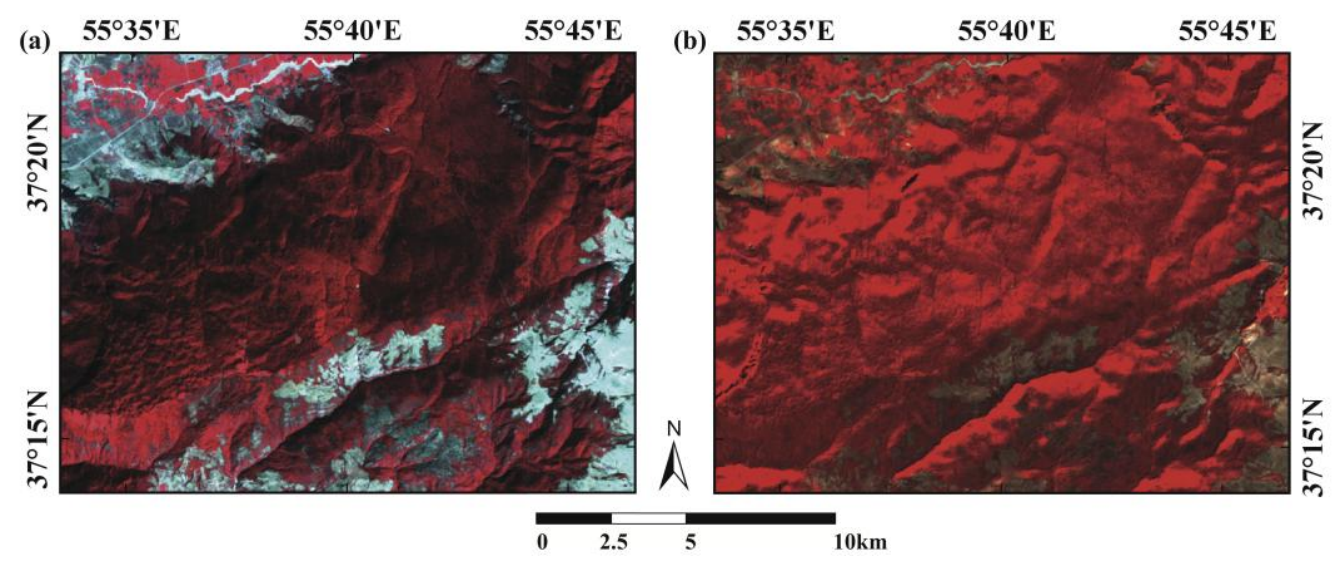

We show the ETM+ reflectance bands before and after topographic correction in Figure 3. Most of the topographic features that can be seen in the original image (Figure 3a) are removed in the corrected image (Figure 3b). Figure 4 shows the ETM+ reflectance before (a) and after (b) topographic correction at the location of field data for different forest classes. The effect of relief and shadows on the surface reflectance is evident. The topographic effects tend to decrease the surface reflectance in both near-infrared (NIR) and shortwave infrared regions (SWIR) due to the shadowing effects introduced by the relief (Figure 4). This is also true for the green spectral region where the reflectance is decreased in the uncorrected scene. At a single perspective, MF2 showed the highest reflectance due 
to the regeneration effects after logging. The logging has led to the more homogeneous canopy structure in MF2; therefore, it has higher reflectance of red and NIR. On the other hand, shadows of emergent trees from MF1 and NF brought more shadowing effects in the canopy structure; therefore, the signal of red and NIR towards the sensor is decreased [52].

Figure 4. Landsat surface reflectance based on the location of field data (a) before and (b) after topographic correction.
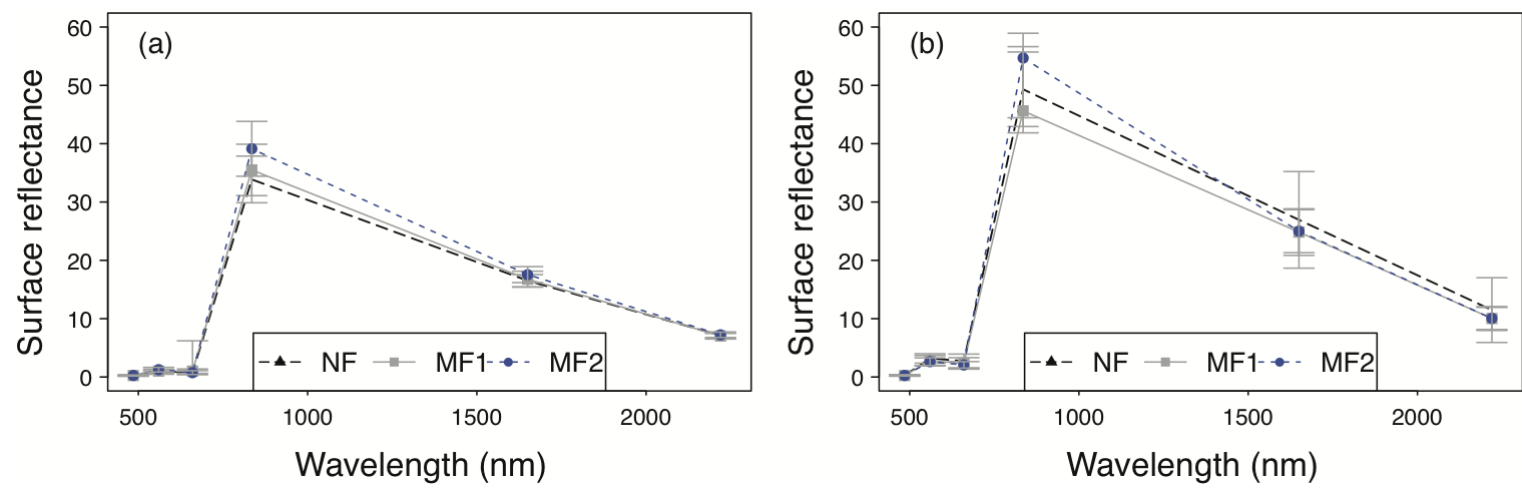

After preprocessing of the ETM+ scene, we calculated the normalized difference vegetation index (NDVI) [53], the principal component analysis (PCA) [54], a tasseled cap transformation (TCT) [55,56] and the gray level co-occurrence matrix (GLCM) [57]. NDVI has been in use for many years to measure and monitor plant growth, vegetation cover and biomass production from multispectral satellite data [53]. However, NDVI loses its sensitivity to dense vegetation because of the saturation in red and near infrared wavelength [11,58-60]. PCA allows redundant data to be compacted into fewer bands. The bands of PCA data (components) are non-correlated and independent, and often can be interpreted better than the source data [54]. However, the first few bands account for a high proportion of the variance in the data [61]. TCT brightness, greenness, and wetness define the vegetation information content $[55,56]$ and are calculated by the linear combination of ETM+ bands. GLCM textures describe the spatial variation of the spectral information in the image [57,62]. As many images contain regions characterized by variation in brightness rather than a unique value, textures can improve image classification [57]. In this study, we used texture filters based on co-occurrence measures by the window size of $11 \times 11$ pixels with horizontal and vertical offset of one. These metrics have been widely used to predict stand forest structure and biomass from remote sensing data $[8,59,63]$.

\subsection{ALOS/PALSAR Processing}

In order to enhance radiometric resolution and to square the pixels in ground range geometry at similar spatial resolution (i.e., $30 \mathrm{~m}$ for Landsat), the amplitude images were multi-looked eight times (i.e., four looks in azimuth and two looks in range) for the dual-polarization scene [64]. After multi-looking, we performed refined Lee filter using a window size of $7 \times 7$ in order to minimize speckle $[65,66]$. The performance of the filter and selection of the optimal window size was evaluated with the speckle suppression and mean preservation index (SMPI; [67]). 
The intensity scenes were converted in their corresponding backscattering coefficients (Sigma nought $(\mathrm{dB}) ; \sigma^{\circ}$ ) values (Equation $\left.(2),[68,69]\right)$. The study area is mountainous, and a strong relief effect is observed. Heterogeneous topography changes the dominant ground-trunk double-bounce scattering mechanism, subsequently the backscatter from forest will be changed [70]. Therefore, we performed radiometric terrain correction to compensate for the ground-topography influence on backscattering coefficient. The corrected backscatter in gamma-nought $\gamma^{\circ}$ format can be obtained from the sigma-nought $\sigma^{\circ}$ value according to Equation (3) [71,72].

$$
\sigma^{\circ}=10 \times \log _{10}\left(\mathrm{I}^{2}+\mathrm{Q}^{2}\right)+\mathrm{CF}-32.0
$$

$\mathrm{CF}$ (calibration factor) $=-83 \mathrm{~dB}, \mathrm{I}$ and $\mathrm{Q}=$ the real and imaginary parts of the complex SAR image pixel values

$$
\gamma^{\circ}=\sigma^{\circ} \frac{A_{\text {flat }}}{A_{\text {slope }}}\left(\frac{\cos \theta_{\text {ref }}}{\cos \theta_{\text {loc }}}\right)^{n}
$$

$\gamma^{\circ}=$ topographic normalized backscattering coefficient, $\sigma^{\circ}=$ radar backscattering coefficient, $A_{\text {flat }}=$ PALSAR pixel size for a theoretical flat terrain, $A_{\text {slope }}=$ true local PALSAR pixel size for the mountain terrain, $\theta_{l o c}=$ local incidence angle, $\theta_{\text {ref }}=$ radar incidence angle at the image center.

The exponent $\mathrm{n}$ is the optical canopy depth and ranges between 0 and 1 . It is a site-specific factor and difficult to obtain in practice, therefore it is set to 1 [19,32,33,73].

We calculated alpha angle $(\alpha)$, entropy $(\mathrm{H})$ and anisotropy $(\mathrm{A})$ according to the decomposition proposed by Cloude and Pottier [74]. This method is based on the extraction of mean diffusion based on eigenvalues/eigenvectors decomposition of the coherence matrix in order to characterize scattering interactions of the beams with the targets [74]. We extracted GLCM SAR textures using a window size of $11 \times 11$ pixels with horizontal and vertical offset of one. Mean, variance, homogeneity, contrast, dissimilarity, second moment and correlation from both $\mathrm{HH}$ and $\mathrm{HV}$ polarization bands were extracted.

Figure 5. (a) HH-HV backscattering (b) alpha-entropy of Cloude-Pottier decomposition on the location of field data for different forest classes. $\left(Z_{6}\right.$ and $Z_{9}$ are dominated by surface scattering, $\mathrm{Z}_{2}, \mathrm{Z}_{5}$ and $\mathrm{Z}_{8}$ by volume scattering and $\mathrm{Z}_{1}, \mathrm{Z}_{4}$ and $\mathrm{Z}_{7}$ by multiple scattering mechanisms. $Z_{3}$ is non-feasible region).

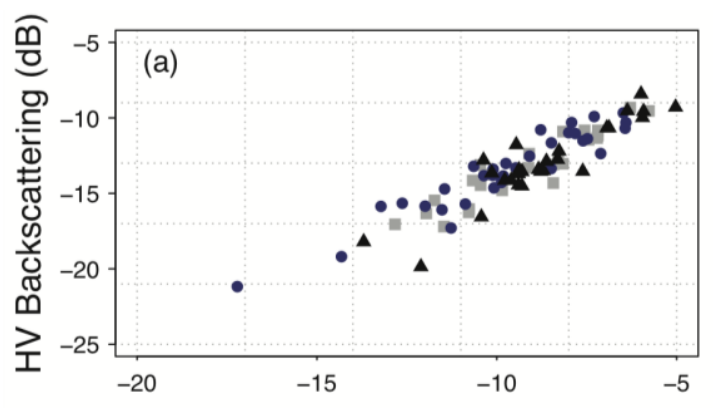

HH Backscattering $(\mathrm{dB})$

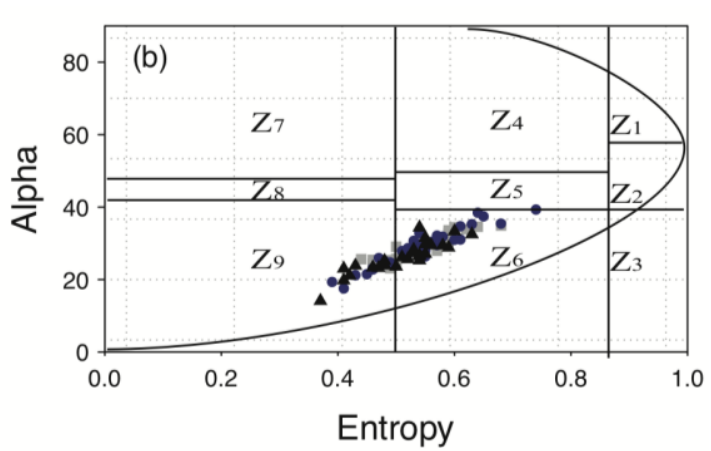

Entropy

\NF $=\mathrm{MF} 1 \bullet \mathrm{MF} 2$

Figure 5a shows the backscattering in $\mathrm{HH}$ and $\mathrm{HV}$ polarized bands, and Figure 5b shows the distribution of alpha angle and entropy on the Cloude-Pottier diagram. The results may be affected by 
the use of dual-polarization data rather than quad-polarization data [13] that were not available for the area. The backscattering values in both $\mathrm{HH}$ and HV polarized bands (Figure 5a) tend to decrease from NF to the both managed forest classes due to a more clear forest floor. Less density of trees per ha might enhance forest backscattering (Figure 5a). In general, there is no substantial difference among different forest classes. This backscattering similarity could be resulted from saturation effect in backscattering value, which is known for forest with high AGB value (i.e., ca. > $100 \mathrm{Mg} / \mathrm{ha}$ ) [19,22,75]. Alpha angle values are below 40 degrees, indicating predominantly surface scattering mechanism [74,76,77].

\subsection{Modeling of Forest $A G B$}

Figure 6 illustrates the whole procedure starting from preprocessing of data in order to develop a forest AGB estimation model from multi-source remote sensing data. Various correlations between forest AGB and the reflectance or vegetation indices were found [63,78-80]. Also, many studies made use of the relation between SAR backscatter/texture and forest AGB [14,24,30,31,81,82].

Figure 6. Flowchart of mountain forest AGB estimation model.

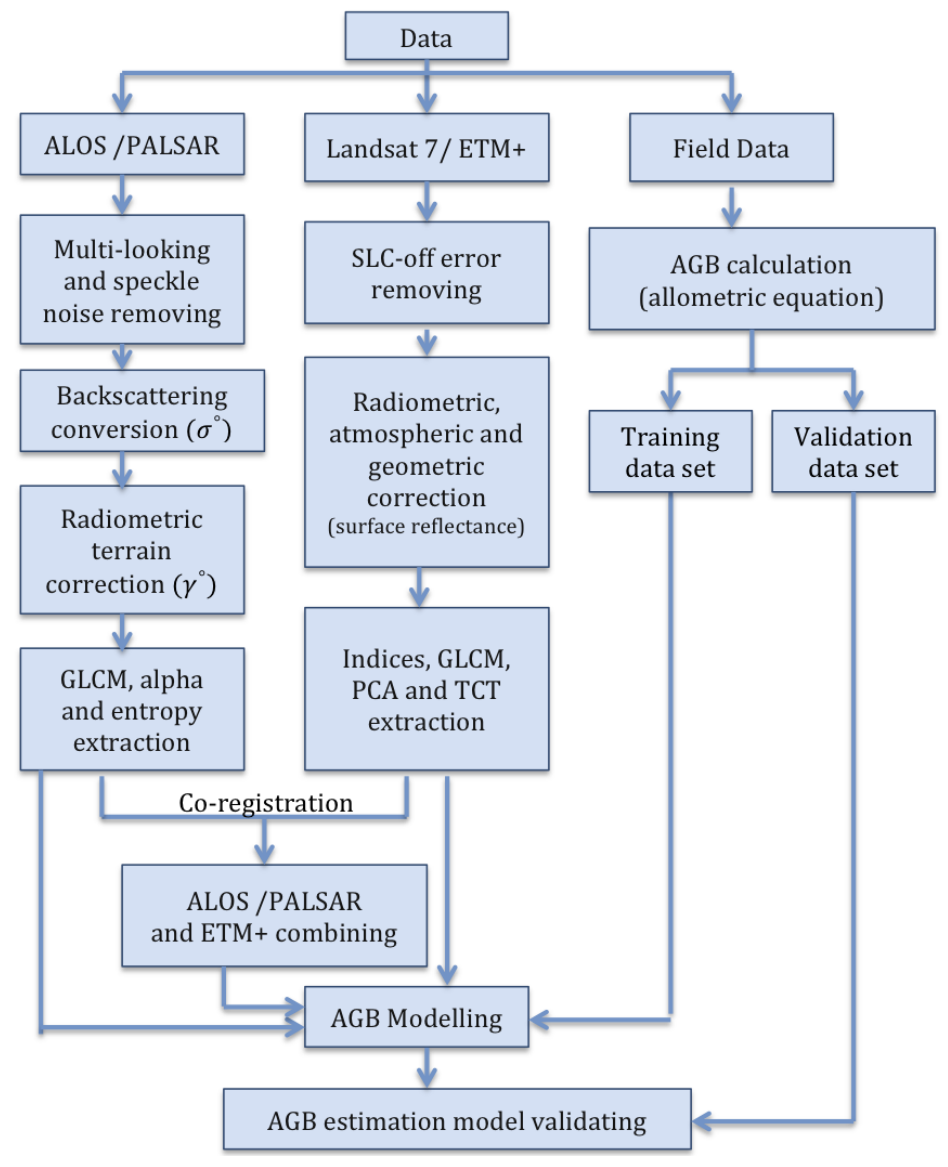

We divided the sample plots into training and validation parts. We used the training plots to develop forest AGB estimation models and validation plots to validate the models and calculate RMSE. In each class, around $30 \%$ of plots are used as validation data. All models are generated at $95 \%$ confidence level $(\alpha=0.05)$, which means that there is a statistically significant relationship between the variables at $95 \%$ confidence interval. In each model, only the parameters with $\mathrm{P}$ value $\leq 0.05$ are included. These parameters are statistically significant parameters to the model. We developed AGB estimation 
model with SAR data and uncorrected ETM+ to verify the effect of topography on mountain forest AGB estimation. We also tested the relation of remote sensing dataset and original DBH measurements to overcome the bias induced by introducing empirical allometric equations. Based on the positive results, we then focused on developing AGB estimation models based on corrected remote sensing data. Table 4 summarizes the datasets and significant parameters to AGB models. Models L1-L5 stand for the forest AGB estimation models, which use the corrected ETM+ reflectance, NDVI and GLCM texture. In models P1-P5, PALSAR backscattering and their textures as well as polarimetric features are used. Final model is the forest AGB estimation model based on ETM+, PALSAR and their derivatives' metrics (Table 4). As we have a large number of independent variables in each model, multicollinearity (a high degree of correlation) may occur among variables. Therefore, we implemented variance inflation factor (VIF) test to detect and remove multicollinearity among variables [83].

Table 4. Datasets and significant parameters for different AGB estimation models.

\begin{tabular}{|c|c|c|c|}
\hline \multicolumn{2}{|c|}{ Model } & Datasets & Significant Parameters $*(\mathbf{P} \leq \mathbf{0 . 0 5})$ \\
\hline \multirow{5}{*}{ Landsat } & L1 & ETM+ bands & b3, b4, b7 \\
\hline & $\mathrm{L} 2$ & ETM+ bands, NDVI & b4, b7, NDVI \\
\hline & L3 & ETM+ bands, NDVI, PCA & b7, PCA-1, PCA-2 \\
\hline & L4 & ETM+ bands, NDVI, PCA, TCT & b7, PCA-1, PCA-2 \\
\hline & L5 & $\begin{array}{c}\text { ETM+ bands, NDVI, PCA, TCT, GLCM } \\
\text { textures }\end{array}$ & $\begin{array}{l}\text { b7, b4, PCA-1, variance b4, variance b5, } \\
\text { correlation b2, correlation b4 }\end{array}$ \\
\hline \multirow{5}{*}{ PALSAR } & $\mathrm{P} 1$ & $\mathrm{HH}, \mathrm{HV}$ & $\mathrm{HH}, \mathrm{HV}$ \\
\hline & $\mathrm{P} 2$ & $\mathrm{HH}, \mathrm{HV}$, polarimetric features & HH, HV, entropy \\
\hline & P3 & $\mathrm{HH}, \mathrm{HV}$, polarimetric features, texture $\mathrm{HH}$ & $\mathrm{HH}, \mathrm{HV}$, entropy, contrast $\mathrm{HH}$, mean $\mathrm{HH}$ \\
\hline & $\mathrm{P} 4$ & $\mathrm{HH}, \mathrm{HV}$, polarimetric features, texture $\mathrm{HV}$ & HH, HV, entropy, mean HV \\
\hline & P5 & $\begin{array}{c}\mathrm{HH}, \mathrm{HV} \text {, polarimetric features, texture } \mathrm{HH} \text {, } \\
\text { texture } \mathrm{HV}\end{array}$ & $\begin{array}{c}\mathrm{HH}, \mathrm{HV} \text {, entropy, contrast } \mathrm{HH} \text {, mean } \mathrm{HH} \text {, } \\
\text { second moment HV }\end{array}$ \\
\hline $\begin{array}{c}\text { Landsat } \\
\& \\
\text { PALSAR }\end{array}$ & Final & $\begin{array}{c}\text { ETM+ bands, PALSAR polarized bands, their } \\
\text { derived features }\end{array}$ & b3, b4, b7, PCA-1, HH, HV, contrast $\mathrm{HH}$ \\
\hline
\end{tabular}

Note: * Significant parameters; parameters with $\mathrm{P}$ values $\leq 0.05$. There are statistically significant relationships between these parameters and AGB at $95 \%$ confidence interval.

Adjusted $\mathrm{R}^{2}$ and $\mathrm{P}$ value of each model were calculated. For validation purposes, we calculated RMSE of each model based on validation dataset. RMSE (Equation (4)) is a frequently used measure of differences between values predicted by the model and the observed values.

$$
R M S E=\sqrt{\frac{1}{n} \sum_{j=1}^{n}(\text { predicted value }- \text { observed value })^{2}}
$$

Normally, a model with high adjusted $\mathrm{R}^{2}$ and low RMSE values implies a good fit between the predicted values (calculated from developed models) and observed value in the field. For all models, one-way ANOVA analysis was done at 0.05 significance level [84]. 


\section{Results and Discussion}

\subsection{Effect of Topographic Correction on Forest AGB Estimation}

In Figures 3 and 4, we show the effect of topographic correction on reflectance in ETM+ Landsat bands. Reflectance in green, NIR, and SWIR is remarkably decreased because of relief effects. This will affect the relationship between AGB and reflectance. We evaluated final forest AGB model with uncorrected ETM+ data. Table 5 summarizes the model. Low adjusted $R^{2}$ (i.e., 0.51), and high RMSE stand for unreliable model. In Figure 7, we plotted the difference between predicted and observed biomass versus the slope for each plot before and after topographic correction. In steeper slope $\left(>10^{\circ}\right)$, the differences are higher compared to gentler slope. The averages of the absolute values of difference between the predicted and observed AGB values for different slope class are reported in Table 6. In all slope groups, the difference is higher for the uncorrected data compared to corrected data. The highest contrast is found in very steep slope $\left(>15^{\circ}\right)$. We concluded that the topographic component has a high influence on AGB estimation in the mountain forest (Table 5). Therefore, we focus on developing AGB estimation model with topographically corrected data.

Table 5. Statistics summary of forest AGB estimation model based on uncorrected $\mathrm{ETM}+$ data.

\begin{tabular}{|c|c|c|c|c|c|}
\hline Model & Dataset & $\begin{array}{l}\text { Significant Parameters * } \\
\qquad(P \leq \mathbf{0 . 0 5})\end{array}$ & RMSE & $\operatorname{Adj} . R^{2}$ & P Value ** \\
\hline $\begin{array}{l}\text { AGB model (Before } \\
\text { topographic correction) }\end{array}$ & $\begin{array}{l}\text { Landsat bands, Landsat textures, } \\
\text { PALSAR bands and their textures }\end{array}$ & $\begin{array}{c}\text { b4, mean b5, contrast b5, HH, HV, } \\
\text { alpha, mean } \mathrm{HH}\end{array}$ & $\begin{array}{c}37.53 \\
(\mathrm{Mg} / \mathrm{ha})\end{array}$ & 0.51 & 0.0000 \\
\hline
\end{tabular}

Note: * Significant parameters; parameters with $\mathrm{P}$ values $\leq 0.05$. There are statistically significant relationships between theses parameters and AGB at $95 \%$ confidence interval. $* *$ When the $\mathrm{P}$ value is $\leq 0.05$, there is a statistically significant relationship between the variables at $95 \%$ confidence level.

Figure 7. Distribution of difference between predicted and observed forest AGB values versus slopes of each plot (a) before (b) and after topographic correction.
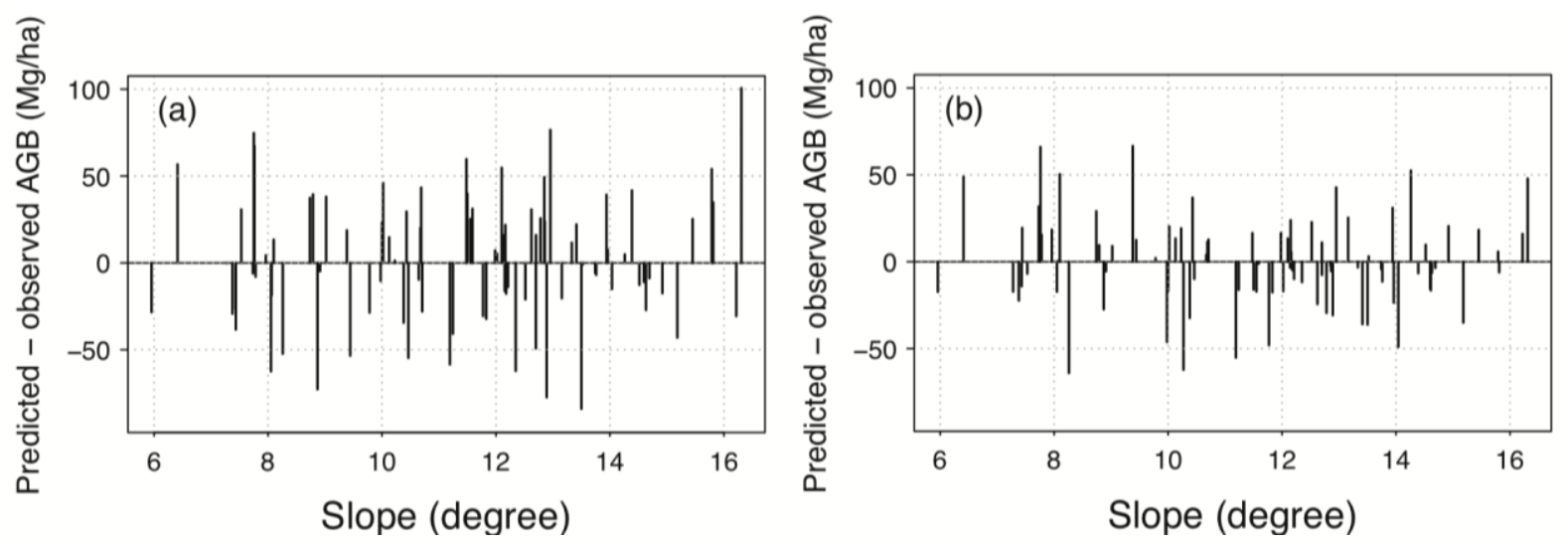

\subsection{Forest AGB Estimation from DBH Data}

We developed AGB estimation model with DBH data (Table 7). The high adjusted $R^{2}$ (i.e., 0.74) and low RMSE (i.e., $3.61 \mathrm{~cm}$ ) indicate that in case the only DBH data are available, they can be 
correlated with remote sensing derived variables to estimate forest parameters at plot level. Figure 8 shows the predicted and observed mean DBH per plot.

Table 6. Average of difference between predicted and observed AGB (Mg/ha) values before and after topographic correction.

\begin{tabular}{ccc}
\hline & \multicolumn{2}{c}{ Difference between Predicted and Observed AGB (Mg/ha) Values } \\
\cline { 2 - 3 } Slope & Before Topographic Correction & After Topographic Correction \\
\hline $6^{\circ}-10^{\circ}$ & 32.7 & 25.18 \\
$10^{\circ}-15^{\circ}$ & 28.22 & 18.99 \\
$>15^{\circ}$ & 48.05 & 21.52 \\
\hline
\end{tabular}

Table 7. Statistics summary of DBH estimation model.

\begin{tabular}{|c|c|c|c|c|c|}
\hline Model & Dataset & Significant Parameters $*(\mathbf{P} \leq \mathbf{0 . 0 5})$ & RMSE & Adj. $R^{2}$ & P Value ** \\
\hline $\begin{array}{l}\mathrm{DBH} \\
\text { model }\end{array}$ & $\begin{array}{l}\text { Landsat bands, Landsat } \\
\text { textures, PALSAR bands } \\
\text { and their textures }\end{array}$ & $\begin{array}{c}\mathrm{b} 3, \mathrm{~b} 4, \mathrm{~b} 7, \text { correlation } \mathrm{b} 4, \text { variance } \mathrm{b} 3 \text {, } \\
\text { second moment } \mathrm{HH}\end{array}$ & $\begin{array}{l}3.61 \\
(\mathrm{~cm})\end{array}$ & 0.74 & 0.0000 \\
\hline
\end{tabular}

Note: * Significant parameters; parameters with $\mathrm{P}$ values $\leq 0.05$. There are statistically significant relationships between theses parameters and AGB at $95 \%$ confidence interval. ** When the $\mathrm{P}$ value is $\leq 0.05$, there is a statistically significant relationship between the variables at $95 \%$ confidence level.

Figure 8. Predicted versus observed forest mean DBH values (validation dataset). Each point represents one field plot. The light blue polygon shows the area of $95 \%$ confidence interval and black solid line represents the regression line.
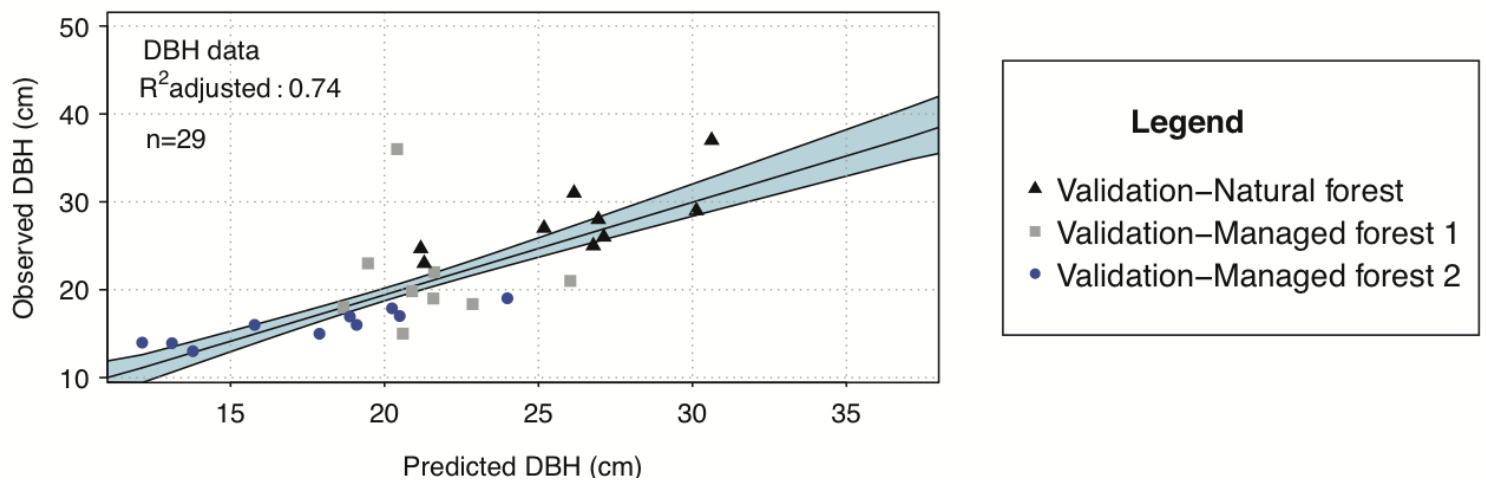

\subsection{Forest AGB Estimation Model Based on Corrected Data}

Table 8 summarizes the RMSE and adjusted $R^{2}$ for all models. In model L1 (Table 4), we use the reflectance of ETM+ to generate the forest AGB estimation model. NDVI and ETM+ spectral bands are used in model L2. In model L3, first and second PCA components as well as ETM+ bands are added to the AGB estimation model (Table 4). However, the attempt to include brightness, greenness and wetness indices to model L4 was ineffective. None of them was statistically significant to the model at $95 \%$ confidence level; therefore, these indices were not added to the model (Table 4). Model L5 uses all textures data as well as principal components and reflectance at ETM+ bands (Table 4). Model L1 describes $38 \%$ the variability of forest AGB in the study area with the RMSE of $49.1 \mathrm{Mg} / \mathrm{ha}$ (Table 8). ANOVA test shows that there is no significant different between L1 and L2 (adjusted $R^{2}$ of 
0.39, RMSE of $49.1 \mathrm{Mg} / \mathrm{ha}$ ) at $5 \%$ significance level (Table 8). This could be because of the saturation of vegetation indices in high biomass forest due to high reflectance $[11,58,59,85]$. Adding PCA components to the model L3 increases the adjusted $R^{2}$ to 0.47 and decreases RMSE to $44.0 \mathrm{Mg} / \mathrm{ha}$ (Table 8). The result is the same for model L4 (Table 8). Because of the inclusion of GLCM textures, Model L5 shows the best result (adjusted $R^{2}=0.59 ; \mathrm{RMSE}=31.5 \mathrm{Mg} / \mathrm{ha}$; Table 8). In heterogeneous forests, texture measures are more sensitive to the canopy structure than spectral reflectance, therefore they correlate better with forest AGB $[11,85,86]$. Band 4 (NIR) and band 7 (MIR), first principal components as well as variance band 4, variance band 5, correlation band 2 and correlation band 4 are the significant parameters (at 95\% interval level) that contribute to the models based on ETM+ data. ANOVA test of models against one another reveals that models L3 and L5 are significantly (at 0.05 significance level) different from model L1.

Results of forest AGB estimation models based on PALSAR backscattering intensity, polarimetric features, and PALSAR texture are as follows. In model P1, we used the backscatter intensity of HH and HV polarization bands (Table 4). In model P2, we also add polarimetric features to the model. SAR textures from HH polarized band are additional input to model P3 compared to model P2. We use $\mathrm{HH}$ and $\mathrm{HV}$ and SAR textures from HV in model P4. In model P5, we use HH, HV, and polarimetric features as well as the textures of HH and HV (Table 4). The adjusted $R^{2}$ and RMSE of model P1 are 0.16 and $58.01 \mathrm{Mg} / \mathrm{ha}$, respectively (Table 8). The week correlation between SAR backscattering coefficients and forest AGB is also reported in previous studies $[25,81,87]$. In model P2, the adjusted $R^{2}$ is increased to 0.25 and RMSE decrease to $47.0 \mathrm{Mg} / \mathrm{ha}$ (Table 8 ). Model P3 describes $41 \%$ the variability of forest AGB in the study area (RMSE $=47.08 \mathrm{Mg} / \mathrm{ha})$. Contrast and mean of $\mathrm{HH}$ are the statistically significant HH-texture at 95\% confidence level (Table 4). In model P4 (adjusted $R^{2}=0.25$; RMSE $=52.01 \mathrm{Mg} / \mathrm{ha}$ ), second moment and mean are the statistically significant texture from $\mathrm{HV}$ polarized band (Table 4). HH and HV backscattering and entropy as well as contrast $\mathrm{HH}$, mean $\mathrm{HH}$, and second moment HV are the most correlated parameters derived from ALOS/PALSAR data (Table 4) in model P5. This model can describe the $45 \%$ variability of the data. RMSE decreases to $43.25 \mathrm{Mg} / \mathrm{ha}$ in this model (Table 8). Saturation of L-band that occurs at high AGB can explain the moderate correlation $[15,19,22,88,89]$. Results from ANOVA test (at 5\% confidence interval) among P1-P5 models confirm that all of the models are significantly different from one another. Higher correlation of model P5 compared to the other models based on PALSAR data could be explained by the sensitivity of SAR textures to forest canopy [90]. Our results are in agreement with the finding of previous studies [90-93].

In the final model, ETM+ and PALSAR data, NDVI and GLCM textures are used (Table 4). The adjusted $R^{2}$ of the final model is 0.76 and RMSE is $25.04 \mathrm{Mg} / \mathrm{ha}$ (Table 8). Bands 3, 4, 7, PCA-1 as well as $\mathrm{HH}, \mathrm{HV}$, and contrast $\mathrm{HH}$ significantly correlate with AGB values (Table 9). Many references choose 5 as a threshold for VIF, also the other recommend 10 for each independent variable [94] or average VIF of 6 for the all selected variables in the model $[95,96]$. We preferred to keep HH-despite the fact that it is highly correlated with HV-because the average VIF of all selected variables is less than 6. Comparison among this model and the other 10 models shows that the joint process of optical and SAR data increase the reliability of model significantly (at 5\% significance level). This model benefits from the complementary nature of the spectral information from ETM+ data and volume 
information from SAR backscattering. The AGB estimation improvement from the inclusion of optical and SAR data is comparable to those reported previously $[6,17,30]$.

Table 8. Forest AGB estimation model parameters.

\begin{tabular}{cccccc}
\hline Model & & RMSE & Adj. $\boldsymbol{R}^{\mathbf{2}}$ & P Value * & ANOVA ** \\
\hline Landsat & L1 & 49.1 & 0.38 & 0.0000 & - \\
& L2 & 49.1 & 0.39 & 0.0000 & - \\
& L3 & 44.0 & 0.47 & 0.0000 & $* *$ \\
& L4 & 44.0 & 0.47 & 0.0000 & $* *$ \\
& L5 & 31.5 & 0.59 & 0.0000 & $* *$ \\
\hline PALSAR & P1 & 58.01 & 0.16 & 0.0002 & $* *$ \\
& P2 & 47.0 & 0.25 & 0.0000 & $* *$ \\
& P3 & 47.08 & 0.41 & 0.0000 & $* *$ \\
& P4 & 52.1 & 0.25 & 0.0010 & $* *$ \\
& P5 & 43.25 & 0.45 & 0.0000 & $* *$ \\
\hline Landsat \& PALSAR & Final & 25.04 & 0.76 & 0.0000 & $* *$ \\
\hline
\end{tabular}

Note: * When the $\mathrm{P}$ value is $\leq 0.05$, there is a statistically significant relationship between the variables at $95 \%$ confidence level. ** Represents the results of ANOVA test; it shows the models that are statistically different at $95 \%$ confidence level.

Table 9. Statistics summary of final forest AGB model.

\begin{tabular}{cccc}
\hline Significant Parameters & Coefficient & P Value & VIF \\
\hline Band 3 & 21.39 & 0.00 & 1.66 \\
Band 4 & 4.85 & 0.04 & 3.13 \\
Band 7 & -18.1 & 0.00 & 2.34 \\
PCA-1 & 14.8 & 0.02 & 1.29 \\
HH & -6.67 & 0.02 & 11.99 \\
HV & 2.87 & 0.05 & 9.5 \\
Contrast HH & -6.63 & 0.01 & 2.39 \\
\hline
\end{tabular}

\subsection{Validation of Forest AGB Models}

Predicted versus observed AGB values are plotted in Figure 9 for the selected models. Figure 10 shows the bar plot of adjusted $R^{2}$ for all models. Model L5 (Figure 9a; Tables 4 and 6) yields moderate results; AGB values between 150 and $210 \mathrm{Mg} / \mathrm{ha}$ are modeled better compare to values out of this range. Underestimations are also observed for very high AGB values (>280 Mg/ha). In Figure $9 \mathrm{~b}$ (model P5; Tables 4 and 6), we observe more overestimating and underestimating compared to model L5. Relatively low adjusted $R^{2}$ and high RMSE show that dual polarimetric SAR cannot properly predict forest AGB. Final model (Figure 9c) based on multisource data is a well-balanced model. The joint processing of ETM+ and ALOS/PALSAR has two significant effects on the biomass estimation. First, it substantially reduces the RMSE error. Second, it leads to the better prediction of medium AGB values ranges from $80-250 \mathrm{Mg} / \mathrm{ha}$. High ABG values are mostly underestimated. 
Figure 9. Predicted versus observed forest AGB (validation dataset); (a) Model L5: based on spectral reflectance and textures of ETM+ scene; (b) Model P5: based on backscattering and derived parameters of ALOS/PALSAR; and (c) Final model: based on ETM+ and ALOS/PALSAR data. Each point represents one field plot. The light blue polygon shows the area of $95 \%$ confidence interval and black solid line represents the fitted line.

(a)

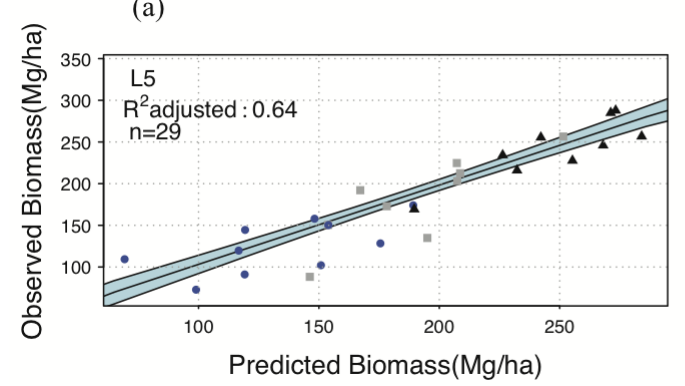

(C)

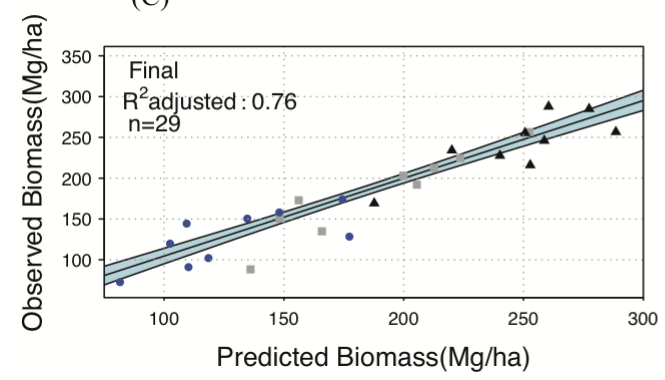

(b)

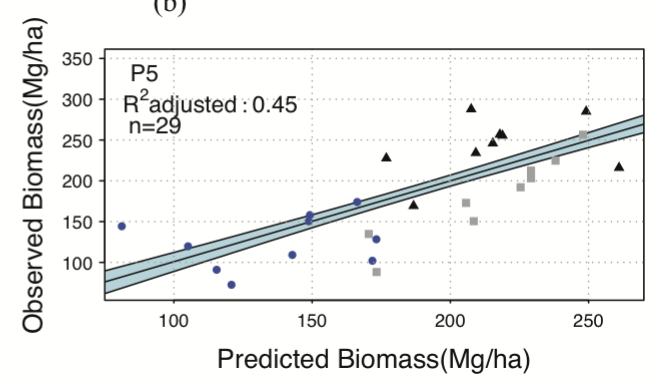

Legend

- Validation-Natural forest

- Validation-Managed forest 1

- Validation-Managed forest 2

Figure 10. Bar plot of $R^{2}$ (refer to Table 4).

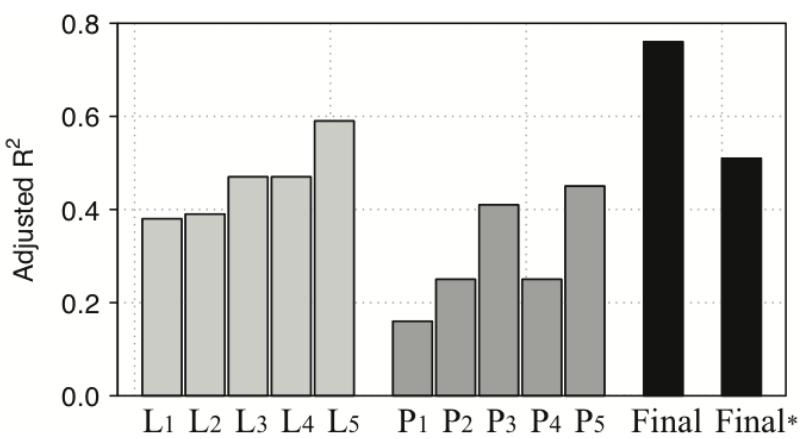

Note: *Final: AGB estimation model based on uncorrected data (Section 4.1).

\subsection{Limitation and Sources of Errors}

We found a reasonable relationship among ETM+ reflectances, SAR backscattering and field measured AGB. However, there are some limitations and sources of errors to our AGB estimation. These include limitation of field measurements and errors introduced by allometric equation and soil and vegetation moisture.

We used the latest inventory data conducted in the study area and the closest remotely sensed data available. Although differences in time acquisitions may bring additional sources of errors in the retrieval of biomass, the inevitable difference of three years between the in-situ measurements and the remote sensing data used was neglected. The AGB estimations would be improved in case they were coincident. Real AGB can only be measured by destructive sampling that is not available for the study. 
The calculated AGB values from allometric equations are accounted for as reference value. Calculations based on allometric equations are the best method when destructive sampling is not performed [21], despite introducing errors by using empirical equations [44]. The other deficiency in observed AGB is that trees with $\mathrm{DBH}<7.5 \mathrm{~cm}$ were excluded from field measurement. They contribute slightly to forest AGB and may impact the SAR backscattering [21].

Soil and vegetation moisture related to the precipitation events impact the SAR backscattering and could be a confounding factor in AGB estimation [89]. L-band SAR can penetrate more through vegetation; thus, the soil backscattering is involved in the total backscattering [21,97]. However, in low biomass densities, soil moisture has more effect on SAR backscattering, since radar signal can penetrate through the trees and hit the surface $[15,21]$.

\section{Recommendations and Conclusions}

This research was the first attempt to apply synthetic aperture radar (SAR) data for above ground dry biomass (AGB) estimation in the Hyrcanian forest. The multiple linear regression procedure clearly demonstrates the feasibility of the joint usage of ETM+ and Advanced Land-Observing Satellite/Phased Array L-band Synthetic Aperture Radar (ALOS/PALSAR) data for the AGB estimation in mountainous and high biomass forests. We conclude that relief influences the forest reflectance and backscatter in mountainous areas; therefore, topographic correction is essential for modeling forest AGB in those regions. Using non-topographically corrected data, the AGB prediction model captured only $51 \%$ of the biomass variability $(\mathrm{RMSE}=37.53 \mathrm{Mg} / \mathrm{ha})$. Adding topographic corrections improved the AGB estimation by up to $25 \%$. Biomass estimation based on ETM+ data shows that gray level co-occurrence matrix (GLCM) textures correlate more with AGB than NDVI and principal component analysis (PCA). Our results showed that the coefficient of correlation could be increased by 0.12 when including texture information. Polarized L-band SAR features alone correlate weakly with AGB (adjusted $R^{2}=0.45, \mathrm{RMSE}=43.25 \mathrm{Mg} / \mathrm{ha}$ ). However, SAR data can be used alternatively when optical data is not available or if the region is covered by clouds. Forest AGB can be modeled more accurately with the joint usage of optical and SAR data (adjusted $R^{2}=0.76$, $\mathrm{RMSE}=25.04 \mathrm{Mg} / \mathrm{ha}$ ) rather than independently (adjusted $R^{2} \leq 0.59$ )

The methodology can be used to produce forest AGB maps in mountainous terrain that can be difficult to obtain with more traditional techniques. Biomass estimations can help managers to measure forest productivity and give them a better vision for further activities. Additional research will explore the influence of full polarimetric L-band SAR data. Although no spaceborne L-band SAR is currently active, some missions such as ALOS/PALSAR-2, Multi-Application Purpose SAR (MAPSAR) and Deformation, Ecosystem Structure and Dynamics of Ice (DESDynI) are planned [20]. Our further research will also focus on the performance of other regression models (e.g., robust regression) for estimating forest AGB based on multisource remote sensing data.

\section{Acknowledgments}

The first author was supported from the German Academic Exchange Service (DAAD) and the International Association of Mathematical Geosciences (IAMG). SAR data was provided under Cat.1-Proposal 6242 through the European Space Agency (ESA) Third Party Mission. The 
Landsat/ETM+, SRTM data and MODIS global land cover product (MOD12) were obtained from USGS. For the correction of SLC-off error, a frame and fill tool-programmed by Richard Irish from NASA Goddard Space Flight Center-was used. We also wish to thank Veraldo Liesenberg (Unicamp/FAPESP) for his contributory feedback on the manuscript. We would like to thank Shaban Shataee from the forestry department, Gorgan University of Agriculture and Natural Science in Iran for providing us with in-situ datasets; without his aid this research would not have been possible.

\section{Author Contributions}

Sara Attarchi prepared and accomplished the study. She also wrote the manuscript. Richard Gloaguen outlined the research, and supported the analysis and discussion. He also supervised the writing of the manuscript at all stages.

\section{Conflicts of Interest}

The authors declare no conflict of interest.

\section{References}

1. Mohammadi, J.; Shataee, S. Possibility investigation of tree diversity mapping using Landsat ETM+ data in the Hyrcanian forests of Iran. Remote Sens. Environ. 2010, 114, 1504-1512.

2. Mohammadi, J.; Shataee, S.; Habashi, H.; Amiri, M. Effect of shelterwood logging on diversity of tree species in the Loveh Forest, Gorgan. Iran. J. For. Poplar Res. 2008, 16, 241-250.

3. Department of Environment, Iran. Forth National Report to the Convention on Biological Diversity; Department of Environment, Iran, 2010; Available online: https://www.cbd.int/doc/ world/ir/ir-nr-04-en.pdf (accessed on 18 April 2014).

4. Main-Knorn, M.; Moisen, G.G.; Healey, S.P.; Keeton, W.S.; Freeman, E.A.; Hostert, P. Evaluating the remote sensing and inventory-based estimation of biomass in the western Carpathians. Remote Sens. 2011, 3, 1427-1446.

5. Soenen, S.A.; Peddle, D.R.; Hall, R.J.; Coburn, C.A.; Hall, F.G. Estimating aboveground forest biomass from canopy reflectance model inversion in mountainous terrain. Remote Sens. Environ. 2010, 114, 1325-1337.

6. Lu, D. The potential and challenge of remote sensing-based biomass estimation. Int. J. Remote Sens. 2006, 27, 1297-1328.

7. Palacios-Orueta, A.; Chuvieco, E.; Parra, A.; Carmona-Moreno, C. Biomass burning emissions: A review of models using remote-sensing data. Environ. Monit. Assess. 2005, 104, 189-209.

8. Zheng, D.; Rademacher, J.; Chen, J.; Crow, T.; Bresee, M.; Le Moine, J.; Ryu, S.-R. Estimating aboveground biomass using Landsat $7 \mathrm{ETM}+$ data across a managed landscape in northern Wisconsin, USA. Remote Sens. Environ. 2004, 93, 402-411.

9. Kronseder, K.; Ballhorn, U.; Böhm, V.; Siegert, F. Above ground biomass estimation across forest types at different degradation levels in Central Kalimantan using LiDAR data. Int. J. Appl. Earth Obs. Geoinf. 2012, 18, 37-48. 
10. Amini, J.; Sumantyo, J.T.S. SAR and Optical Images for Forest Biomass Estimation; In Biomass-Detection, Production and Usage; Matovic, D., Ed.; InTech: Rijeca, Croatia, 2011; pp. 53-74.

11. Eckert, S. Improved forest biomass and carbon estimations using texture measures from WorldView-2 satellite data. Remote Sens. 2012, 4, 810-829.

12. Gibbs, H.K.; Brown, S.; Niles, J.O.; Foley, J.A. Monitoring and estimating tropical forest carbon stocks: Making REDD a reality. Environ. Res. Lett. 2007, doi:10.1088/1748-9326/2/4/045023.

13. Liesenberg, V.; Gloaguen, R. Evaluating SAR polarization modes at L-band for forest classification purposes in Eastern Amazon, Brazil. Int. J. Appl. Earth Obs. Geoinf. 2013, 21, $122-135$.

14. Le Toan, T.; Beaudoin, A.; Riom, J.; Guyon, D. Relating forest biomass to SAR data. IEEE Trans. Geosci. Remote Sens. 1992, 30, 403-411.

15. Luckman, A.; Baker, J.; Kuplich, T.M.; da Costa Freitas Yanasse, C.; Frery, A.C. A study of the relationship between radar backscatter and regenerating tropical forest biomass for spaceborne SAR instruments. Remote Sens. Environ. 1997, 60, 1-13.

16. Castel, T.; Guerra, F.; Caraglio, Y.; Houllier, F. Retrieval biomass of a large Venezuelan pine plantation using JERS-1 SAR data. Analysis of forest structure impact on radar signature. Remote Sens. Environ. 2002, 79, 30-41.

17. Cutler, M.; Boyd, D.; Foody, G.; Vetrivel, A. Estimating tropical forest biomass with a combination of SAR image texture and Landsat TM data: An assessment of predictions between regions. ISPRS J. Photogramm. Remote Sens. 2012, 70, 66-77.

18. Wolter, P.T.; Townsend, P.A. Multi-sensor data fusion for estimating forest species composition and abundance in northern Minnesota. Remote Sens. Environ. 2011, 115, 671-691.

19. Santoro, M.; Fransson, J.E.; Eriksson, L.E.; Magnusson, M.; Ulander, L.M.; Olsson, H. Signatures of ALOS PALSAR L-band backscatter in Swedish forest. IEEE Trans. Geosci. Remote Sens. 2009, 47, 4001-4019.

20. Cartus, O.; Kellndorfer, J.; Rombach, M.; Walker, W. Mapping canopy height and growing stock volume using Airborne Lidar, ALOS PALSAR and Landsat ETM+. Remote Sens. 2012, 4, 3320-3345.

21. Robinson, C.; Saatchi, S.; Neumann, M.; Gillespie, T. Impacts of spatial variability on aboveground biomass estimation from L-band radar in a temperate forest. Remote Sens. 2013, 5, 1001-1023.

22. Imhoff, M.L. Radar backscatter and biomass saturation: Ramifications for global biomass inventory. IEEE Trans. Geosci. Remote Sens. 1995, 33, 511-518.

23. Saatchi, S.; Marlier, M.; Chazdon, R.L.; Clark, D.B.; Russell, A.E. Impact of spatial variability of tropical forest structure on radar estimation of aboveground biomass. Remote Sens. Environ. 2011, 115, 2836-2849.

24. Ranson, K.; Sun, G. Mapping biomass of a northern forest using multifrequency SAR data. IEEE Trans. Geosci. Remote Sens. 1994, 32, 388-396.

25. Rignot, E.; Way, J.; Williams, C.; Viereck, L. Radar estimates of aboveground biomass in boreal forests of interior Alaska. IEEE Trans. Geosci. Remote Sens. 1994, 32, 1117-1124. 
26. Harrell, P.; Bourgeau-Chavez, L.; Kasischke, E.; French, N.; Christensen, N, Jr. Sensitivity of ERS-1 and JERS-1 radar data to biomass and stand structure in Alaskan boreal forest. Remote Sens. Environ. 1995, 54, 247-260.

27. Richards, J.A.; Sun, G.-Q.; Simonett, D.S. L-band radar backscatter modeling of forest stands. IEEE Trans. Geosci. Remote Sens. 1987, 487-498.

28. Craig Dobson, M.; Ulaby, F.T.; Pierce, L.E. Land-cover classification and estimation of terrain attributes using synthetic aperture radar. Remote Sens. Environ. 1995, 51, 199-214.

29. Wang, Y.; Davis, F.; Melack, J.; Kasischke, E.; Christensen, N., Jr. The effects of changes in forest biomass on radar backscatter from tree canopies. Int. J. Remote Sens. 1995, 16, 503-513.

30. Rauste, Y. Multi-temporal JERS SAR data in boreal forest biomass mapping. Remote Sens. Environ. 2005, 97, 263-275.

31. Ahmed, R.; Siqueira, P.; Bergen, K.; Chapman, B.; Hensley, S. A Biomass Estimate Over the Harvard Forest Using Field Measurements with Radar and Lidar Data. In Proceedings of 2010 IEEE International Geoscience and Remote Sensing Symposium (IGARSS), Honolulu, HI, USA, 25-30 July 2010; pp. 4768-4771.

32. Thiel, C.J.; Thiel, C.; Schmullius, C.C. Operational large-area forest monitoring in Siberia using ALOS PALSAR summer intensities and winter coherence. IEEE Trans. Geosci. Remote Sens. 2009, 47, 3993-4000.

33. Kim, C. Quantataive analysis of relationship between ALOS PALSAR backscatter and forest stand volume. J. Mar. Sci. Technol. 2012, 20, 624-628.

34. He, Q.-S.; Cao, C.-X.; Chen, E.-X.; Sun, G.-Q.; Ling, F.-L.; Pang, Y.; Zhang, H.; Ni, W.-J.; Xu, M.; Li, Z.-Y.; et al. Forest stand biomass estimation using ALOS PALSAR data based on LiDAR-derived prior knowledge in the Qilian Mountain, western China. Int. J. Remote Sens. 2011, 33, 710-729.

35. Sun, G.; Ranson, K.J.; Kharuk, V.I. Radiometric slope correction for forest biomass estimation from SAR data in the Western Sayani Mountains, Siberia. Remote Sens. Environ. 2002, 79, 279-287.

36. Liu, W.; Song, C.; Schroeder, T.A.; Cohen, W.B. Predicting forest successional stages using multitemporal Landsat imagery with forest inventory and analysis data. Int. J. Remote Sens. 2008 , 29, 3855-3872.

37. Mosadegh, A. Silviculture; Tehran University Publications: Tehran, Iran, 1996.

38. Marvie Mohadjer, M. Silviculture; Tehran University Publications: Karaj, Iran, 2005.

39. Amiri, M.; Dargahi, D.; Azadfar, D.; Habashi, H. Comparison of structure of the natural and managed Oak (Quercus castaneifolia) stand (shelter wood system) in Forest of Loveh, Gorgan. J. Agric. Sci. Nat. Resour. 2009, 15, 45-56.

40. Amiri, M.; Habashi, H.; Azadfar, D.; Soleymani, N. Comparison of regeneration density and species diversity in managed and natural stands of Loveh Oak forest. J. Agric. Sci. Nat. Resour. 2008, 28, 44-53.

41. Mohammadi, J.; Shataei, S.; Yaghmaei, F.; Salman Mahini, A. Forest stand age classification using Landsat ETM+ data. J. Wood For. Sci. Technol. 2009, 16, 43-59.

42. Martin, J.G.; Kloeppel, B.D.; Schaefer, T.L.; Kimbler, D.L.; McNulty, S.G. Aboveground biomass and nitrogen allocation of ten deciduous southern Appalachian tree species. Can. J. For. Res. 1998, 28, 1648-1659. 
43. Zianis, D.; Mencuccini, M. On simplifying allometric analyses of forest biomass. For. Ecol. Manag. 2004, 187, 311-332.

44. Ahmed, R.; Siqueira, P.; Hensley, S.; Bergen, K. Uncertainty of forest biomass estimates in north temperate forests due to allometry: Implications for remote sensing. Remote Sens. 2013, 5, 3007-3036.

45. West, G.B.; Brown, J.H.; Enquist, B.J. A general model for the structure and allometry of plant vascular systems. Nature 1999, 400, 664-667.

46. Niklas, K.J.; Midgley, J.J.; Enquist, B.J. A general model for mass-growth-density relations across tree-dominated communities. Evol. Ecol. Res. 2003, 5, 459-468.

47. Boloorani, A.D.; Erasmi, S.; Kappas, M. Multi-source remotely sensed data combination: Projection transformation gap-fill procedure. Senors 2008, 8, 4429-4440.

48. Gap Phase Statistic Calculator. Available online: https://landsat.usgs.gov/gap_phase_tool.php (accessed on 4 April 2014),

49. Chen, J.; Zhu, X.; Vogelmann, J.E.; Gao, F.; Jin, S. A simple and effective method for filling gaps in Landsat ETM+ SLC-off images. Remote Sens. Environ. 2011, 115, 1053-1064.

50. Tutorial for Using the NASA Gap Filling Software. Available online: biodiversityinformatics.amnh.org/file.php?file_id=619 (accessed on 4 April 2014),

51. Richter, R.; Schläpfer, D. Atmospheric/Topographic Correction for Satellite Imagery; 565-02/11; DLR-German Aerospace Center: Wessling, Germany, 2011; p. 202.

52. Liesenberg, V.; Boehm, H.-D.V.; Gloaguen, R. Spectral variability and discrimination assessment in a tropical peat swamp landscape using CHRIS/PROBA data. GISci. Remote Sens. 2010, 47, $541-565$.

53. Tucker, C.J. Red and photographic infrared linear combinations for monitoring vegetation. Remote Sens. Environ. 1979, 8, 127-150.

54. Jensen, J.R. Introductory Digital Image Processing: A Remote Sensing Perspective; Prentice-Hall Inc.: Upper Saddle River, NJ, USA, 1996.

55. Crist, E.P.; Kauth, R. The tasseled cap de-mystified. Photogramm. Eng. Remote Sens. 1986, 52, 81-86.

56. Crist, E.P.; Laurin, R.; Cicone, R.C. Vegetation and Soils Information Contained in Transformed Thematic Mapper Data. In Proceedings of IGRASS'86 Symposium, Zurich, Switzerland, 8-11 September 1986; ESA Publ. Division: Noordwijk, The Netherlands, 1986; pp. 1465-1470..

57. Haralick, R.M.; Shanmugam, K.; Dinstein, I.H. Textural features for image classification. IEEE Trans. Syst. Man Cybern. 1973, 3, 610-621.

58. Huete, A.R.; Liu, H.; van Leeuwen, W.J. The Use of Vegetation Indices in Forested Regions: Issues of Linearity and Saturation. In Proceedings of 1997 IEEE International Geoscience and Remote Sensing Symposium, Singapore, 3-8 August 1997; European Space Agency Publications Division: Noordwijk, The Netherlands, 1997; pp. 1966-1968.

59. Lu, D.; Mausel, P.; Brondızio, E.; Moran, E. Relationships between forest stand parameters and Landsat TM spectral responses in the Brazilian Amazon Basin. For. Ecol. Manag. 2004, 198, 149-167.

60. Mutanga, O.; Skidmore, A.K. Narrow band vegetation indices overcome the saturation problem in biomass estimation. Int. J. Remote Sens. 2004, 25, 3999-4014. 
61. Taylor, P.J. Quantitative Methods in Geography: An Introduction to Spatial Analysis; Houghton Mifflin Boston: Boston, MA, USA, 1977.

62. Holden, J. An Introduction to Physical Geography and the Environment; Pearson Education: Upper Saddle River, NJ, USA, 2005.

63. Sader, S.A.; Waide, R.B.; Lawrence, W.T.; Joyce, A.T. Tropical forest biomass and successional age class relationships to a vegetation index derived from Landsat TM data. Remote Sens. Environ. 1989, 28, 143-198.

64. Lee, J.-S.; Hoppel, K.W.; Mango, S.A.; Miller, A.R. Intensity and phase statistics of multilook polarimetric and interferometric SAR imagery. IEEE Trans. Geosci. Remote Sens. 1994, 32, 1017-1028.

65. Lee, J.-S. Refined filtering of image noise using local statistics. Comput. Graph. Image Process. 1981, 15, 380-389.

66. Cantalloube, H.; Nahum, C. How to Compute a Multi-look SAR Image? In Proceedings of SAR Workshop: CEOS Committee on Earth Observation Satellites Working Group on Calibration and Validation, Toulouse, France, 26-29 October 1999; Harris, R.A., Ouwehand, L., Eds.; European Space Agency: Paris, France, 2000; pp. 635-640.

67. Shamsoddini, A.; Trinder, J.; Wagner, W.; Székely, B. Image texture preservation in speckle noise suppression. Int. Arch. Photogramm. Remote Sens. Spat. Inf. Sci. 2010, 38, 239-244.

68. Shimada, M.; Isoguchi, O.; Tadono, T.; Isono, K. PALSAR radiometric and geometric calibration. IEEE Trans. Geosci. Remote Sens. 2009, 47, 3915-3932.

69. Lavalle, M.; Wright, T. Absolute radiometric and polarimetric calibration of ALOS PALSAR products. Available online: http://earth.eo.esa.int/pcs/alos/palsar/articles/Calibration_palsar_products_v13.pdf (accessed on 23 April 2014)

70. Folkesson, K.; Smith-Jonforsen, G.; Ulander, L.M. Model-based compensation of topographic effects for improved stem-volume retrieval from CARABAS-II VHF-band SAR images. IEEE Trans. Geosci. Remote Sens. 2009, 47, 1045-1055.

71. Ulander, L.M. Radiometric slope correction of synthetic-aperture radar images. IEEE Trans. Geosci. Remote Sens. 1996, 34, 1115-1122.

72. Castel, T.; Beaudoin, A.; Stach, N.; Stussi, N.; Le Toan, T.; Durand, P. Sensitivity of space-borne SAR data to forest parameters over sloping terrain. Theory and experiment. Int. J. Remote Sens. 2001, 22, 2351-2376.

73. Lucas, R.; Armston, J.; Fairfax, R.; Fensham, R.; Accad, A.; Carreiras, J.; Kelley, J.; Bunting, P.; Clewley, D.; Bray, S. An evaluation of the ALOS PALSAR L-band backscatter-Above ground biomass relationship Queensland, Australia: Impacts of surface moisture condition and vegetation structure. IEEE J. Sel. Top. Appl. Earth Obs. Remote Sens. 2010, 3, 576-593.

74. Cloude, S.R.; Pottier, E. An entropy based classification scheme for land applications of polarimetric SAR. IEEE Trans. Geosci. Remote Sens. 1997, 35, 68-78.

75. Watanabe, M.; Shimada, M.; Rosenqvist, A.; Tadono, T.; Matsuoka, M.; Romshoo, S.A.; Ohta, K.; Furuta, R.; Nakamura, K.; Moriyama, T. Forest structure dependency of the relation between L-band and biophysical parameters. IEEE Trans. Geosci. Remote Sens. 2006, 44, 3154-3165. 
76. Ouarzeddine, M.; Belhdj Aissa, A.; Souissi, B.; Belkhider, M.; Boulahbal, S. Polarimetric Classification Using the Cloude/Pottier Decomposition. In Proceedings of the 2nd International Workshop POLINSAR 2005, Frascati, Italy, 17-21 January 2005; Lacoste, H., Ed.; ESA Publications Division: Noordwijk, The Netherlands, 2005.

77. Lonnqvist, A.; Rauste, Y.; Molinier, M.; Hame, T. Polarimetric SAR data in land cover mapping in boreal zone. IEEE Trans. Geosci. Remote Sens. 2010, 48, 3652-3662.

78. Roy, P.; Ravan, S.A. Biomass estimation using satellite remote sensing data-An investigation on possible approaches for natural forest. J. Biosci. 1996, 21, 535-561.

79. Steininger, M. Satellite estimation of tropical secondary forest above-ground biomass: Data from Brazil and Bolivia. Int. J. Remote Sens. 2000, 21, 1139-1157.

80. Hall, R.; Skakun, R.; Arsenault, E.; Case, B. Modeling forest stand structure attributes using Landsat ETM+ data: Application to mapping of aboveground biomass and stand volume. For. Ecol. Manag. 2006, 225, 378-390.

81. Dobson, M.C.; Ulaby, F.T.; LeToan, T.; Beaudoin, A.; Kasischke, E.S.; Christensen, N. Dependence of radar backscatter on coniferous forest biomass. IEEE Trans. Geosci. Remote Sens. 1992, 30, 412-415.

82. Kuplich, T.; Salvatori, V.; Curran, P. JERS-1/SAR backscatter and its relationship with biomass of regenerating forests. Int. J. Remote Sens. 2000, 21, 2513-2518.

83. Belsley, D.; Kuh, E.; Welsch, R. Regression Diagnostics: Identifying Influential Data and Sources of Collinearity; Wiley \& Sons, Inc.: Hoboken, NJ, USA, 1980.

84. Chambers, J.M.; Hastie, T. Statistical models in S; Chapman \& Hall/CRC: Pacific Grove, CA, USA, 1992.

85. Lu, D. Aboveground biomass estimation using Landsat TM data in the Brazilian Amazon. Int. J. Remote Sens. 2005, 26, 2509-2525.

86. Sarker, L.R.; Nichol, J.E. Improved forest biomass estimates using ALOS AVNIR-2 texture indices. Remote Sens. Environ. 2011, 115, 968-977.

87. Foody, G.M.; Green, R.; Lucas, R.; Curran, P.; Honzak, M.; Do Amaral, I. Observations on the relationship between SIR-C radar backscatter and the biomass of regenerating tropical forests. Int. J. Remote Sens. 1997, 18, 687-694.

88. Lucas, R.M.; Mitchell, A.L.; Rosenqvist, A.; Proisy, C.; Melius, A.; Ticehurst, C. The potential of L-band SAR for quantifying mangrove characteristics and change: case studies from the tropics. Aquat. Conserv.: Mar. Freshw. Ecosys. 2007, 17, 245-264.

89. Morel, A.C.; Saatchi, S.S.; Malhi, Y.; Berry, N.J.; Banin, L.; Burslem, D.; Nilus, R.; Ong, R.C. Estimating aboveground biomass in forest and oil palm plantation in Sabah, Malaysian Borneo using ALOS PALSAR data. For. Ecol. Manag. 2011, 262, 1786-1798.

90. Sarker, M.L.R.; Nichol, J.; Ahmad, B.; Busu, I.; Rahman, A.A. Potential of texture measurements of two-date dual polarization PALSAR data for the improvement of forest biomass estimation. ISPRS J. Photogramm. Remote Sens. 2012, 69, 146-166.

91. Kuplich, T.; Curran, P.; Atkinson, P. Relating SAR image texture to the biomass of regenerating tropical forests. Int. J. Remote Sens. 2005, 26, 4829-4854.

92. Luckman, A.; Frery, A.; Yanasse, C.; Groom, G. Texture in airborne SAR imagery of tropical forest and its relationship to forest regeneration stage. Int. J. Remote Sens. 1997, 18, 1333-1349. 
93. Champion, I.; Dubois-Fernandez, P.; Guyon, D.; Cottrel, M. Radar image texture as a function of forest stand age. Int. J. Remote Sens. 2008, 29, 1795-1800.

94. Kutner, M.H.; Nachtsheim, C.J.; Neter, J.; Li, W. Applied Linear Statistical Models; McGraw-Hill/Irwin: New York, NY, USA, 2004.

95. Pedhazur, E.J. Multiple Regression in Behavioral Research: Explanation and Prediction; Harcourt Brace College Publishers: San Diego, CA, USA, 1997.

96. Ender, P.B. Applied Categorical \& Nonnormal Data Analysis. Available online: http://www.philender.com/courses/categorical/notes2/collin.html (accessed on 1 April 2014).

97. Wang, X.; Ge, L.; Li, X. Pasture monitoring using SAR with COSMO-SkyMed, ENVISAT ASAR, and ALOS PALSAR in Otway, Australia. Remote Sens. 2013, 5, 3611-3636.

(C) 2014 by the authors; licensee MDPI, Basel, Switzerland. This article is an open access article distributed under the terms and conditions of the Creative Commons Attribution license (http://creativecommons.org/licenses/by/3.0/). 